\title{
Gradual failure in high-performance unidirectional thin-ply carbon/glass hybrid composites under bending
}

\author{
Guillermo Idarraga $^{\mathrm{a}, *}$, Meisam Jalalvand ${ }^{\mathrm{b}}$, Mohamad Fotouhi ${ }^{\mathrm{c}}$, Juan Meza ${ }^{\mathrm{a}}$, Michael R. Wisnom ${ }^{\mathrm{d}, *}$ \\ ${ }^{a}$ National University of Colombia, Design of Advanced Composite Structures DADCOMP, 75th Street 79A-56, Building M17, Medellín, Colombia \\ ${ }^{\mathrm{b}}$ Engineering Materials, School of Engineering, University of Southampton, SO17 1BJ Southampton, United Kingdom \\ ${ }^{\mathrm{c}}$ University of Glasgow, School of Engineering, Glasgow G12 8QQ UK \\ ${ }^{\mathrm{d}}$ Bristol Composites Institute (ACCIS), University of Bristol, Bristol BS8 1TR, UK
}

\section{A R T I C L E I N F O}

\section{Keywords:}

Bending

Hybrid composites

Gradual failure

Fragmentation and delamination

\begin{abstract}
A B S T R A C T
This paper introduces new composite architectures using carbon and glass fibre-reinforced epoxy prepregs to achieve gradual failure under bending. The concept is based on a technique developed by the authors to design hybrid composites with gradual failure in tension combined with beam theory to identify and control the failure sequence of the plies in the layups. Two layups are designed based on standard ply thickness S-Glass and hybrid sub-laminates made out of intermediate and high modulus thin-ply carbon prepregs. The layups are tested under 4-point bending loading where a gradual failure alongside high values of flexural displacement are achieved. No catastrophic failure is observed throughout the whole loading process. The gradual layerby-layer failure of the surface layers on the tensile side produces a brush-like appearance. Microscopy observations from interrupted tests verified fragmentation of the high-modulus carbon layer followed by gradual failure of the intermediate modulus carbon layer and delamination on the tensile side, as well as stable shear cracks of the high-modulus carbon layer on the compression side.
\end{abstract}

\section{Introduction}

Lightweight design is becoming increasingly important in various industries, particularly in aerospace, wind energy and automotive applications. Fibre-reinforced composites are attracting more interest for such weight-sensitive applications owing to their excellent stiffness, strength with a low density. However, the failure of common composites is usually sudden and catastrophic, with no notable sign of prior damage or any warning. To ensure safe operations, typically greater safety factors are applied for composite components than for those made out of traditional homogeneous ductile materials. This condition may produce overdesigned composite structures, losing the real potential weight-saving benefits. Achieving gradual failure in composites can help structures to maintain functionality even when they are overloaded, widening their application scope.

One of the successful approaches for introducing gradual failure into composite materials and avoiding catastrophic failure is hybridisation [1-8]. By combining different types of low strain materials (LSM) and high strain materials (HSM) and selecting an appropriate configuration, it is possible to obtain a gradual failure process and non- linear stress-strain response. In general, three different possibilities for hybridisation have been widely used: interlayer, intralayer and intrayarn. The interlayer hybrid configuration, where the mixing of different materials occurs on the ply level, has been the most exploited method because of its simpler production [5]. Extensive experimental work, as well as analytical and numerical modelling, have been conducted in recent years on the tensile loading case [9-13]. These studies have demonstrated successful gradual failure in glass/carbon and carbon/carbon hybrid composites using thin-ply prepregs. Thin carbon/ epoxy pre-impregnated plies produced using the recently developed tow spreading technology have been important to suppress damage mechanisms by obtaining lower energy release rates, delaying the propagation of intralaminar and interlaminar cracks [14-18]. This characteristic allowed introducing fragmentation of thin-ply carbon layers as a new damage mechanism in the hybrid composites without catastrophic failure.

Four types of failure procedures are recognised for Uni-Directional (UD) hybrid composites under tension [19]. These are schematically illustrated in Fig. 1a alongside their stress-strain schematic response: 1) premature high strain material (HSM) failure after the first crack

\footnotetext{
* Corresponding authors.

E-mail addresses: gaidarra@unal.edu.co (G. Idarraga), M.Wisnom@bristol.ac.uk (M.R. Wisnom).
} 


\section{(1) Premature high strain material failure}
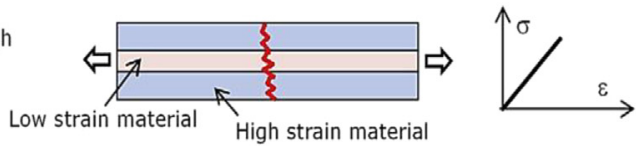

(2) Catastrophic delamination
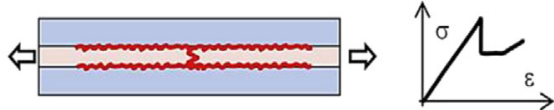

\section{(3) Low strain material fragmentation}
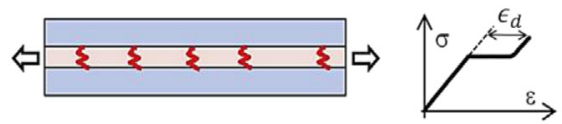

(4) Low strain material fragmentation and dispersed delamination
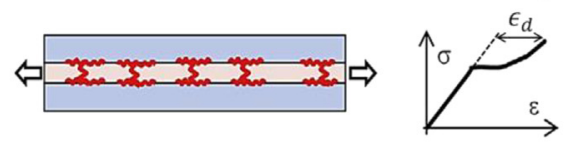

(a)

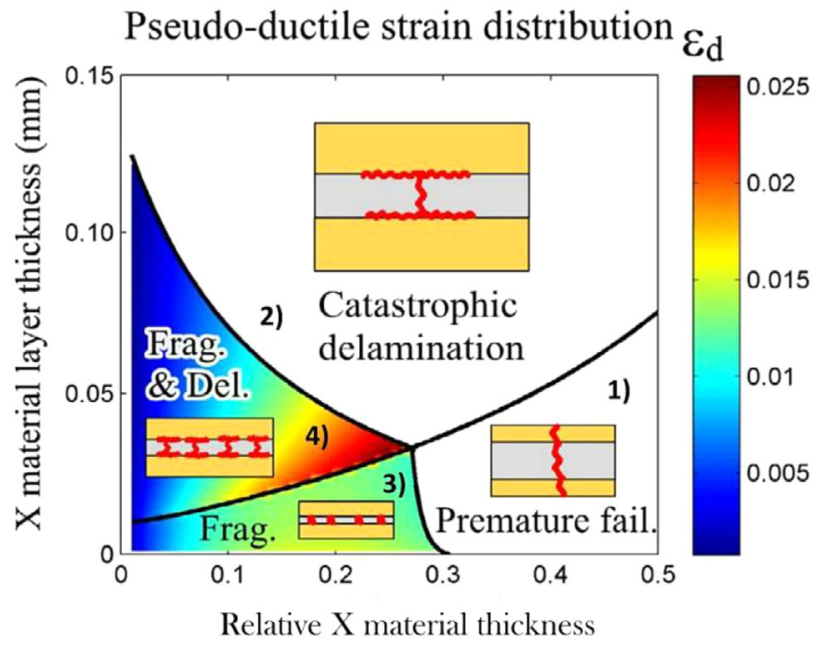

(b)

Fig. 1. a) Four possible damage scenarios in UD hybrid composite laminates, b) Damage Mode Map of an arbitrary hybrid combination (adapted from Refs. $[19 ; 20])$.

in the low strain material (LSM), 2) catastrophic delamination at the interface between the LSM and HSM after the first crack in the LSM, 3) fragmentation of the LSM and 4) fragmentation of the LMS followed by limited dispersed delamination. The first two failure modes are unfavourable and their behaviour in the stress-strain graphs is characterised by a significant load drop, leading to mechanical properties lower than the constituents. Damage modes 3 and 4 are desirable because they provide integrity and load carrying capacity while the laminate is gradually deteriorating. The stress-strain graphs obtained from these failure processes are characterised by a plateau after the linear-elastic part of the curve. This plateau is produced by a gradual reduction in the relative contribution of the LSM plies in carrying load due to fragmentation. As fragmentation progresses the load-carrying contribution of the fragmented LSM plies is further reduced. Once fragmentation reaches saturation, further load is carried by the HSM plies producing an increasing trend in the stress-strain curve. The pseudo-ductile strain $\left(\varepsilon_{d}\right)$ for damage modes 3 and 4 , shown in Fig. 1a, is defined as the extra strain obtained due to gradual failure and is measured between the final failure point and the initial slope line at the failure stress level. The pseudo-ductile strain $\left(\varepsilon_{d}\right)$ for damage modes 1 and 2 is zero because the loss of integrity due to premature failure or catastrophic delamination.
Using the analytical method proposed in [19], it is possible to find a correlation between the four types of failure modes described before and the geometric parameters of any specific material combination. Using those correlations, damage mode maps have been proposed as an efficient method to find optimum configurations of different UD hybrid combinations to achieve gradual failure [20]. Fig. 1b shows schematically a damage mode map, where the horizontal axis in the map corresponds to the relative LSM thickness, the thickness of LSM plies divided by the total hybrid's thickness, and the vertical axis shows the absolute thickness of the LSM plies. The map shows the different damage sceneries separated by boundaries, correlating the damage type zone with the geometric parameters (total LSM proportion and absolute LSM layers thickness). The coloured bar in the map indicates the pseudo-ductile strain $\left(\varepsilon_{d}\right)$, which measures the favourable gradual failure for damage modes 3 and 4 , being a maximum close to the intersection of the three boundaries between different damage modes.

Bending is an important loading scenario in real applications and most of the structures are subject to bending loads. However, achieving gradual failure under bending has not been the focus of research studies yet to the authors' best knowledge. Most of the research has concentrated on preventing failure initiation, maximising the flexural strength and modulus in both unidirectional and multidirectional hybrid composites by optimising stacking configurations [21-24]. Different works [25-28] have demonstrated that the stacking sequence plays an important role in the performance of glass/carbon hybrid composites under bending conditions. Unsymmetrical layups yield the highest flexural strength when the glass layers are placed on the compressive side $[25,26,28]$. Replacing lower elongation carbon fibres with higher elongation glass fibres in compression improves the overall flexural performance of the composites and delays compressive failure mechanisms.

New hybrid composites with gradual failure under bending can significantly increase the potential application opportunities of composite materials. In high-performance applications, this can help to avoid overdesigned structures, and enhance the reliability of the structures. A few works have studied hybrid composites under bending [29-33], however, the failure process was catastrophic, with relatively low flexural displacements. This paper introduces a new concept to design asymmetric hybrid composites that fail in a gradual process when loaded under bending. Catastrophic compressive failure is avoided using glass layers on the compressive side of the beam, which retains its structural integrity all the way through the failure process until it is unloaded. The hybrid laminate on the tensile side is designed using the authors' analytical model published in [19] and [20] to obtain gradual failure in tension and the concept is further explored experimentally.

\section{Material and configuration design}

\subsection{Concept}

Due to the compressive strength of fibre reinforced composites along the fibre direction being generally much lower than their tensile strength [34], it is common to observe that the failure initiates on the compression side in non-hybrid UD laminates under bending. The dominant compressive failure mode in UD composites is microbuckling, which is usually a catastrophic process. To achieve gradual failure in bending in this paper, the hybrid beam is designed to avoid compressive failure initiation and to promote gradual failure initiation on the tensile side. To do that, the hybrid layups are designed using different materials for the compressive and tensile side. Using the Sglass/epoxy with higher compressive failure strain than the tensile failure strain of the applied M55 and T1000 carbon/epoxy should guarantee tensile failure initiation. The material and the sub- 
laminate in tension are selected to produce a gradual stiffness reduction by fragmentation and stable pull out with increasing strain.

The layups proposed are hybrid carbon/glass composites, using standard thickness S-Glass on the compressive side and thin-ply carbon/carbon hybrid sub-laminates on the tensile side. The carbon/carbon hybrid sub-laminates are repeated through the thickness as a "building block" to obtain the desired total thickness. The building block corresponds to a basic unit made out of intermediate and high modulus thin-ply carbon prepregs: (IM Carbon $\mathrm{i}_{\mathrm{i}} / \mathrm{HM} \mathrm{Carbon}_{\mathrm{k}} / \mathrm{IM}$ Carbon $_{\mathrm{i}}$ ) where $\mathrm{i}$ and $\mathrm{k}$, are the number of plies selected for each material. Using damage mode maps, the building blocks were designed to guarantee initial fragmentation of the high modulus carbon layer without catastrophic failure of the intermediate modulus carbon layer.

\subsection{Materials}

For the compressive side, standard ply thickness prepregs made of S-Glass with 913 epoxy resin system with a compressive failure strain of $2.33 \%$ are used [31], which were supplied by Hexcel. For the tensile part of the beam, it was decided to make hybrid sub-laminates out of T1000 and M55 thin-ply carbon/epoxy prepregs from North Thin Ply Technology (NTPT). The T1000 intermediate modulus (IM) carbon fibres have a tensile failure strain of $2.2 \%$ and the tensile failure strain of M55 high modulus (HM) carbon fibres is reported to be $0.8 \%$ [11]. The choice of fibres in tension was based on having enough difference between the tensile failure strain values of the constituents and at the same time, avoiding very low tensile failure strains at damage initiation. Additionally, the results published in [6] showed that hybridising HM M55/epoxy with IM T1000/epoxy provided good results in terms of pseudo-ductile strain and gradual failure in tension.

The lower tensile failure strain of M55 will contribute to obtain failure initiation in tension. While M55 has a relatively low compressive failure strain, the beam is designed to have most of the M55 layers on the tensile side. The few M55 layers on the compressive side are relatively close to the neutral axis and therefore the compressive strain they experience is less than the tensile strain experienced by the M55 layers on the tensile side. Accounting for the lower compressive than tensile failure strain, the margin between the M55 layer's compressive failure strain and the experienced compressive strain is still larger than the margin for the bottom M55 layers in tension due to the distance of these layers from the neutral axis. Therefore, failure is expected to initiate in the M55 layers on the tensile side, rather than on the compressive side.

The epoxy resin in both prepreg layer systems in tension are ThinPreg 120 EPHTg-402 (North TPT). The curing temperature implemented for all the resin systems in the used prepregs is $125{ }^{\circ} \mathrm{C}$. Although no chemical analysis on the compatibility of both resin systems was done, previous experience indicated a good bonding between both resin systems [6]. Table 1 shows the basic properties of the applied materials.

\subsection{Design of hybrid laminate building blocks}

Proposing the building block architecture is the first step to design the full layups. Different combinations of M55 and T1000 layers were assessed using damage mode maps. Fig. 2 shows the four possible failure processes of the M55/T1000 hybrids. Details of how this map is plotted are explained in [20]. The circles in the map represent the position of four different building block configurations and the coloured regions of the map indicate the favourable pseudo-ductile strain $\left(\varepsilon_{d}\right)$ in the regions with gradual failure. Building blocks 1 and 2 are located in the fragmentation zone, building block 3 is located in the fragmentation and local delamination zone and building block 4 produces catastrophic delamination. The damage analysis was carried out using a mode II critical strain energy release rate of $\mathrm{G}_{\mathrm{IIC}}=0.5 \mathrm{~N} / \mathrm{mm}$. This critical value was selected based on observations conducted in [6] during tests on similar hybrid configurations made of prepregs comprising the same epoxy matrix systems (Thin-Preg 120 EPHTg-402 North TPT). Table 2 shows the geometric parameters, Young's modulus and mode II energy release rate, $\mathrm{G}_{\mathrm{II}}$, at the M55 fibre failure strain of $0.8 \%$ (see Table 1 ). According to [4], the energy release rate $\left(\mathrm{G}_{\mathrm{II}}\right)$ must be lower than the mode II critical energy release rate $\left(\mathrm{G}_{\text {IIC }}=0.5\right)$ of the interface to avoid catastrophic delamination of the central M55 layer after its first fracture. This criterion is introduced in Eq. (1), which is satisfied by all building blocks proposed, except by building

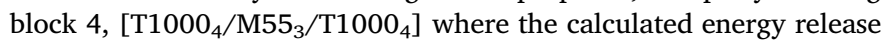
rate $\mathrm{G}_{\mathrm{II}}$ is $0.69 \mathrm{~N} / \mathrm{mm}$ at the failure strain of the M55 fibre, $0.8 \%$.

$G_{I I}=\frac{\varepsilon_{2 b}^{2} E_{2} t_{2}\left(2 E_{1} t_{1}+E_{2} t_{2}\right)}{8 E_{1} t_{1}}<G_{I I C}$

where $E_{1}$ and $E_{2}$ are the elastic modulus of the T1000 and M55 layers. $t_{1}$ is the thickness of each block of T1000 on either side, $t_{2}$ is half of the laminate thickness of M55 and $\varepsilon_{2 b}$ is the failure strain of M55. $G_{I I}$ is the energy release rate and $G_{I I C}$ is the mode II critical energy release rate.

Layups 1, 2 and 3 are located in the desirable area of the map where the failure is expected to be gradual. However, building block 3 has four layers of T1000 on each side. If this block is repeated through the thickness, eight layers of T1000 will be placed next to each other separating the M55 plies, while using building blocks 1 and 2, the M55 plies will be separated by only two and four layers of T1000. The lower number of T1000 layers of building blocks 1 and 2 may contribute to having a more distributed and gradual failure through the thickness. Therefore, building blocks 1 and 2 were chosen for the experiments and the rest of the analysis.

Using the analytical method proposed by [19], the strain-stress response of the building blocks 1 and 2 is calculated as shown in Fig. 3. Building block 1 has slightly higher initial stiffness and damage initiation stress (knee point A on the blue curve) and building block 2 has a higher margin between damage initiation (knee point $A$ on the orange curve) and final failure (point B on the orange curve). Both configurations show acceptable pseudo-ductility behaviour in tension and they are expected to produce gradual failure in bending.

\subsection{Full layup design using beam theory}

Different configurations were analysed using beam theory to calculate the strain distribution through the thickness. The aim is to design a beam configuration in which the glass layers under compression do not fail before the failure initiation on the tensile side of the beam. A

Table 1

Cured ply properties of the applied UD prepregs.

\begin{tabular}{|c|c|c|c|c|}
\hline Prepreg Material & Elastic Modulus [GPa] & Tensile Failure Strain [\%] & Compression Failure Strain [\%] & Cured ply thickness [mm] \\
\hline S-Glass/913 & $45.7[31]$ & $3.98[31]$ & $2.33[31]$ & $0.155[31]$ \\
\hline T1000/Thin-Preg 120 EPHTg-402 & $143.3[11]$ & $2.2^{\text {a }}$ & $0.95^{\mathrm{b}}$ & $0.032[11]$ \\
\hline M55/Thin-Preg 120 EPHTg-402 & $280.0[11]$ & $0.8^{\mathrm{a}}$ & $0.56[33]$ & $0.030[11]$ \\
\hline
\end{tabular}

a Fibre tensile failure strain based on manufacturer's data.

b Based on manufacturer's data for $60 \%$ fibre volume fraction. 


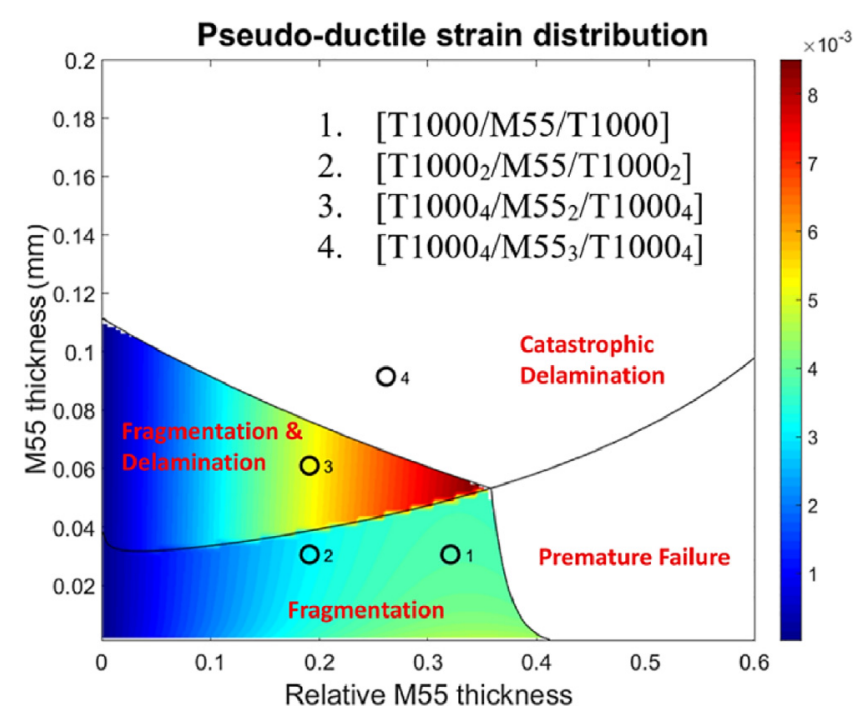

Fig. 2. Damage mode map of M55/T1000 hybrid layups.

MATLAB code, with the algorithm explained in Fig. 4, was implemented to find the required failure bending moment of each layer through the thickness, based on the compressive and tensile failure strains reported in Table 1.

The material properties of each layer, geometric parameters, and the stacking sequence of the laminates are the code inputs. Using this input data, the code calculates the transformation function using the Young's modulus of S-Glass as the baseline $E_{1}$. Then, the code identifies the position of the neutral axis. Finally, the code calculates the required failure bending moment for each ply based on its failure strain. The code provides an idea of the failure initiation of the laminate, producing a failure sequence where the plies with lowest failure bending moment fail first.

Using the code, different layup configurations were analysed and the following two layups are proposed for the experimental tests:

- Layup 1: [S-Glass $\left.7 / M 55 / T 1000 /(T 1000 / M 55 / T 1000)_{17} / \mathrm{T} 1000\right]$ using building block 1

- Layup 2: [S-Glass $7 / \mathrm{T} 1000 / \mathrm{M} 55 / \mathrm{T} 1000_{2} /\left(\mathrm{T} 1000_{2} / \mathrm{M} 55 /\right.$ T1000 2$)_{10}$ ] using building block 2

Both layups have the same total thickness to make them directly comparable, but with different ratios of T1000 to M55. For the layup 1 compared with layup 2, one ply of T1000 was relocated from the top side (close to the S-Glass) to the bottom face, in order to have the same number of T1000 layers covering the external M55 ply in tension and promote a similar failure initiation in both layups. Seven layers of SGlass were proposed for the compression side as this number of layers allows a safe margin between the compressive failure of the S-Glass and the tensile failure of the T1000/M55 hybrid. This should ensure that compression failure is avoided.

In Fig. 4, $\mathrm{E}$ is the young modulus, $\widehat{\varepsilon}$ is the failure strain, $\mathrm{w}$ is the width and $\mathrm{t}$ is the thickness of the different layers. $N_{i}$ is the transforma- tion function to account for the different moduli, $A_{i}$ is the weighted cross-section area of each layer including the transformation function, $y_{N A}$ is the location of the neutral axis, $y_{i}$ corresponds to the distance between the base of the layup (bottom face) and the centroid of layer $i, I_{X X}$ is the layer second moment of area, $\bar{y}_{i}$ is the distance between layer $i$ centroid and the neutral axis, $M_{i}$ is the failure moment and $\left|C_{i}\right|$ is the absolute distance between the bottom surface of layer $i$ to the neutral axis. For all the equations the sub-index $i$ correspond to the layer number $i$, for $i$ from 1 to the total number of layers.

Fig. 5 and Fig. 6 show the position of each layer on the vertical axis and the required bending moment for the failure of each layer on the horizontal axis. The blue stars, red dots and green squares correspond to the S-Glass, T1000 and M55 layers respectively. The blue dashed lines indicate the location of the neutral axis and the black dashed line indicates the lowest required failure bending moment. The code calculates the total bending moment required to break each layer using the failure strain in tension or compression depending on the ply position. Layers with lower required failure bending moment will fail first. Since the main objective is to verify the initial failure order and guarantee that the failure initiation is promoted in tension, the code does not consider the stiffness reduction of the layups because of ply failure as well as the shift of the neutral axis.

For both layups, the layers most likely to fail first correspond to the M55 ply in tension (number 1 in the failure order), followed by the top M55 ply in compression close to the S-Glass (number 2 in the failure order). According to Figs. 5 and 6, compressive failure of the S-Glass layer requires a significantly higher bending moment, therefore failure initiation and catastrophic failure on the compression side is avoided. Despite the top M55 layer under compression appearing likely to fail as the second layer in the failure order, it has been observed that M55 under compression can lead to fragmentation rather than catastrophic failure [31,32]. Additionally, once the first layer fails in tension, the neutral axis will move upward, reducing the risk of compressive failure. Therefore, the design is still considered likely to avoid premature compressive failure.

\section{Experimental}

\subsection{Specimen manufacturing}

The interlayer hybrid specimens were made by stacking the specified glass and carbon prepregs on top of each other. Laminates were cured in an autoclave at the recommended cure temperature and pressure cycle for Hexcel 913 resin $\left(60 \mathrm{~min} @ 125^{\circ} \mathrm{C}\right.$ and $0.7 \mathrm{MPa}$ ), as this is similar to the NTPT thin carbon prepreg cure cycle. The individual specimens were cut with a diamond cutting wheel. Six samples were obtained from each plate. Table 3 shows the dimensions of the manufactured samples.

\subsection{Test method}

Four-point bending (4-PB) test setup was selected to achieve a constant bending moment in the middle of the beam. This assures that carbon layer failure takes place between the loading noses where the bending moment is maximum and constant whereas the shear stresses

Table 2

Building block properties.

\begin{tabular}{|c|c|c|c|c|}
\hline Building Block & Total Thickness $[\mathrm{mm}]$ & M55 Relative Thickness [-] & Predicted Modulus [GPa] & Calculated $\mathrm{G}_{\mathrm{II}}$ at $0.8 \%$ Strain as the failure of M55 $[\mathrm{N} / \mathrm{mm}]^{\text {a }}$ \\
\hline 1. [T1000/M55/T1000] & 0.095 & 0.323 & 186.6 & 0.26 \\
\hline 2. $\left[\mathrm{T} 1000_{2} / \mathrm{M} 55 / \mathrm{T} 1000_{2}\right]$ & 0.160 & 0.193 & 169.3 & 0.19 \\
\hline 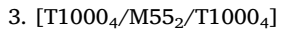 & 0.320 & 0.193 & 169.3 & 0.39 \\
\hline 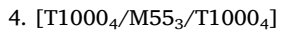 & 0.351 & 0.263 & 178.9 & 0.69 \\
\hline
\end{tabular}

a Mode II energy release rate $\mathrm{G}_{\mathrm{II}}$ calculated using Eq. (1). 


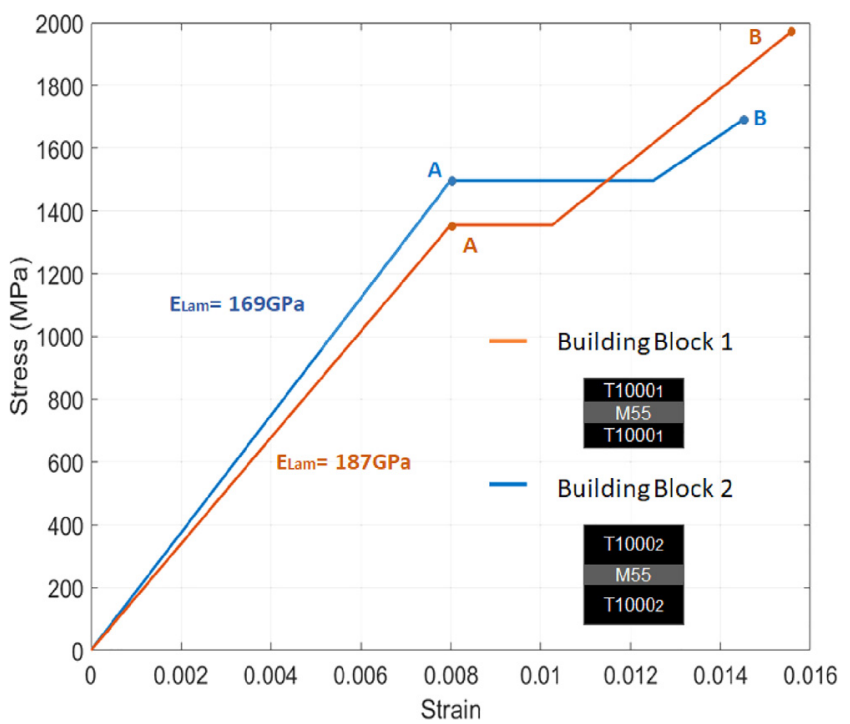

Fig. 3. The tensile response of building block 1 [T1000/M55/T1000] and building block 2 [T10002/M55/T10002].

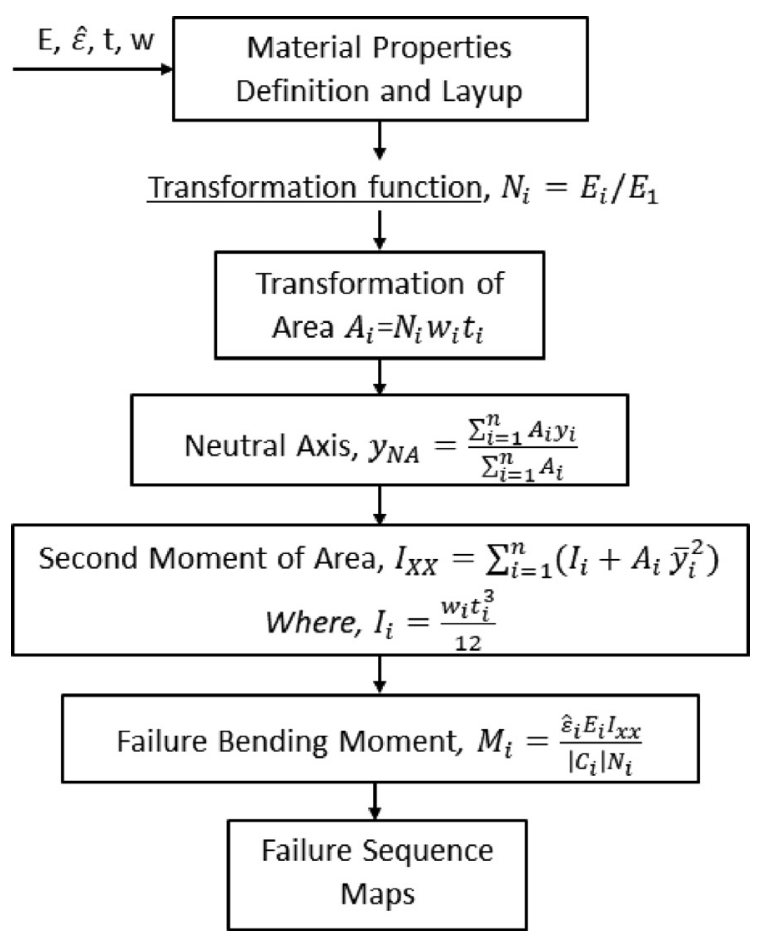

Fig. 4. MATLAB code to generate the failure sequence diagram and strain and stress distribution diagrams.

are relatively small. Rubber pads were used between the loading noses and the samples to reduce the high and concentrated contact stresses. Fig. 7 shows the schematic of the specimen geometry and the test setup including the calculated neutral axis position which is $1.049 \mathrm{~mm}$ and $1.067 \mathrm{~mm}$ from the bottom of layup 1 and 2 respectively. The distance between the bottom supports is $120 \mathrm{~mm}$, the distance between the inner loading noses is $25 \mathrm{~mm}$ and the diameter of all supports and loading noses are $10 \mathrm{~mm}$. Four-point bending loading on the prismatic specimens was executed at a constant $3 \mathrm{~mm} / \mathrm{min}$ crosshead speed on a computer-controlled Instron 8872 type $25 \mathrm{kN}$ rated universal servo-hydraulic test machine with a regularly calibrated $10 \mathrm{kN}$ rated load cell. Load and displacement were measured

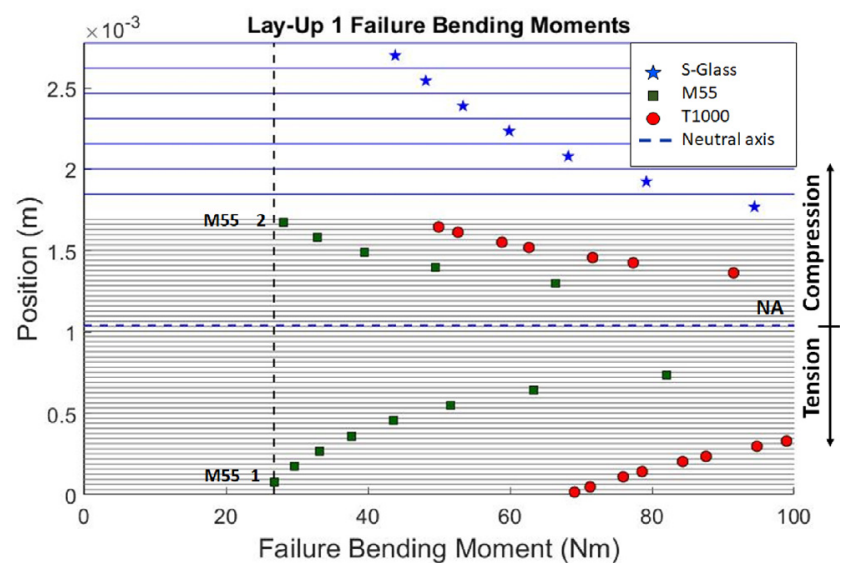

Fig. 5. Bending moments for each layer showing the failure sequence of layup 1, [S- Glass ${ }_{7} /$ M55/T1000/(T1000/M55/T1000) $\left.{ }_{17} / \mathrm{T} 1000\right]$.

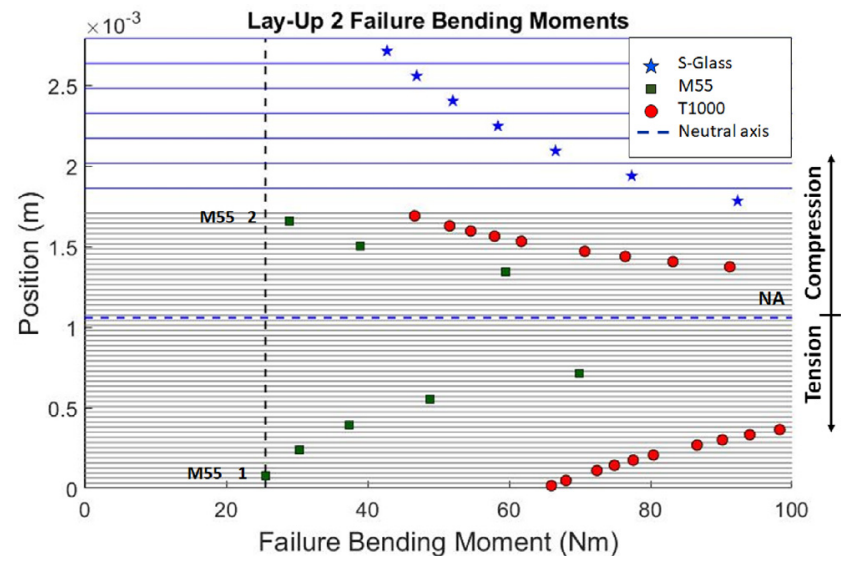

Fig. 6. Bending moments for each layer showing the failure sequence of layup 2, [S-Glass $\left.7 / \mathrm{T} 1000 / \mathrm{M} 55 / \mathrm{T}_{1000} /\left(\mathrm{T} 1000_{2} / \mathrm{M}_{2} 5 / \mathrm{T}_{1000}\right)_{10}\right]$.

Table 3

Dimensions of the manufactured samples.

\begin{tabular}{llll}
\hline Spec. type & Length $(\mathrm{mm})$ & Width $(\mathrm{mm})$ & Thickness $(\mathrm{mm})$ \\
\hline Layup 1 & $190 \pm 0.19$ & $19.93 \pm 0.10$ & $2.92 \pm 0.05$ \\
Layup 2 & $190 \pm 0.34$ & $20.38 \pm 0.05$ & $2.96 \pm 0.08$ \\
\hline
\end{tabular}

from the machine and the strains were measured using a strain gauge located on the bottom carbon ply of each sample as shown in Fig. 7. Videos of the specimens were recorded for failure analysis and process characterisation.

\subsection{Microscopy observations}

Two samples were interrupted earlier in order to observe the failure inside the layup under the microscope. The interrupted samples of each layup were observed using a Nikon Eclipse LV100 optical microscope. A section between the inner loading noses of the interrupted samples was cut using a diamond saw and embedded in Veracril, a self-curing acrylic resin. To take the micrographs closer to the middle of the sample and avoid edge defects, $5 \mathrm{~mm}$ was ground off from the width of the samples using 240 grit SiC sandpaper and water as the lubricant. The samples were polished with 2000 grit $\mathrm{SiC}$ sandpaper and then using colloidal silica down to $0.05 \mu \mathrm{m}$ on a 


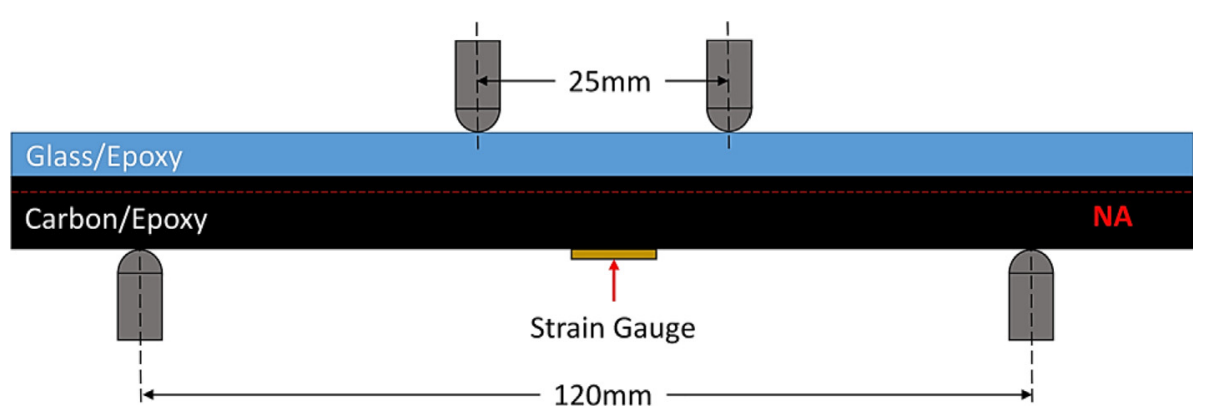

Fig. 7. Schematic of the four-point bending (4-PB) test setup.

chemically-resistant no-nap polishing cloth in a VibroMet grinding machine.

\section{Results and discussion}

\subsection{Test results}

The layups designed using the method proposed in section 2.4 show a successful gradual failure, displaying a brush-like appearance as shown in Fig. 8. $60 \mathrm{~mm}$ maximum vertical displacement at the loading noses was achieved without failure through the full thickness. The tests were stopped when the samples were moved from the supporting rollers to the edge of the support block square as shown in Fig. 8a.

Fig. 9 shows the load-displacement graph for both layups. Both groups of samples show high non-linearity after $1.2 \mathrm{kN}$ and before the load drops. This behaviour is due to both non-linear geometric deformation and M55 layer fragmentation. Matching the time of the recorded videos and the load-displacement data provided by the machine and considering the large difference in the failure order between M55 and T1000 plies, it is concluded that the load drops shown in the load-displacement graphs in Fig. 9 are related to the failure of T1000 layers followed by instantaneous delamination of the T1000/M55 hybrid blocks from the undamaged part of the beam. Layup 2 reached a slightly higher maximum load of $1.70 \mathrm{kN}$ than that of layup 1, which is $1.60 \mathrm{kN}$. These results are in agreement with Fig. 3 where Layup 2 (building block 2) shows a slightly higher failure stress. The total energy absorbed by elastic deformation, fragmentation and delamination of each specimen is calculated by integrating the area under the load-displacement curve up to a maximum applied displacement of $35 \mathrm{~mm}$. Both configurations give fairly close average absorbed energy of $150.8 \mathrm{~kJ}$ for layup 1 and $155.4 \mathrm{~kJ}$ for layup 2 . The reason to compare both layups only up to $35 \mathrm{~mm}$ applied transverse displacement is that around $36 \mathrm{~mm}$ applied displacement, the beam touches the corner of the support block and loses contact with the support roller.

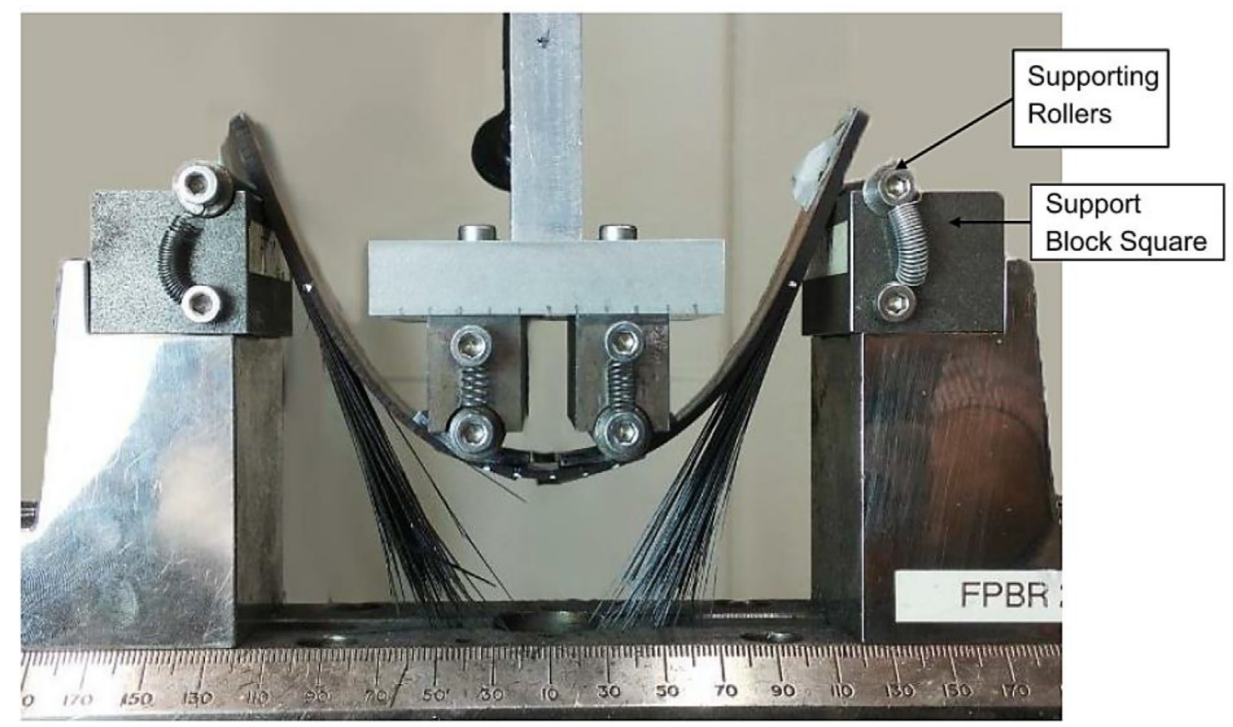

(a)

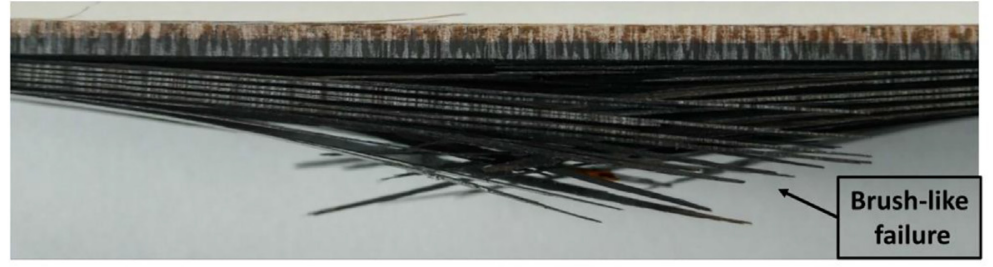

(b)

Fig. 8. Four-point bending (4-PB) test, (a) high displacement results (b) brush-like failure appearance after the test. 


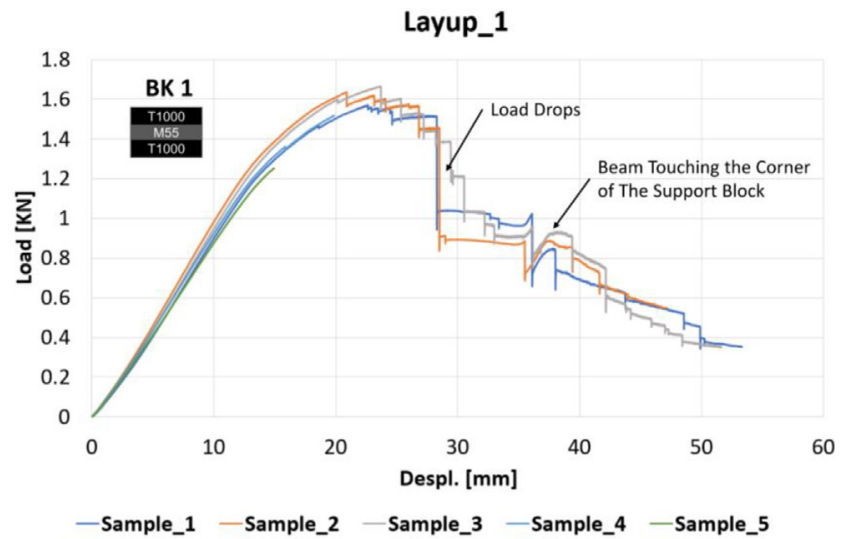

(a)

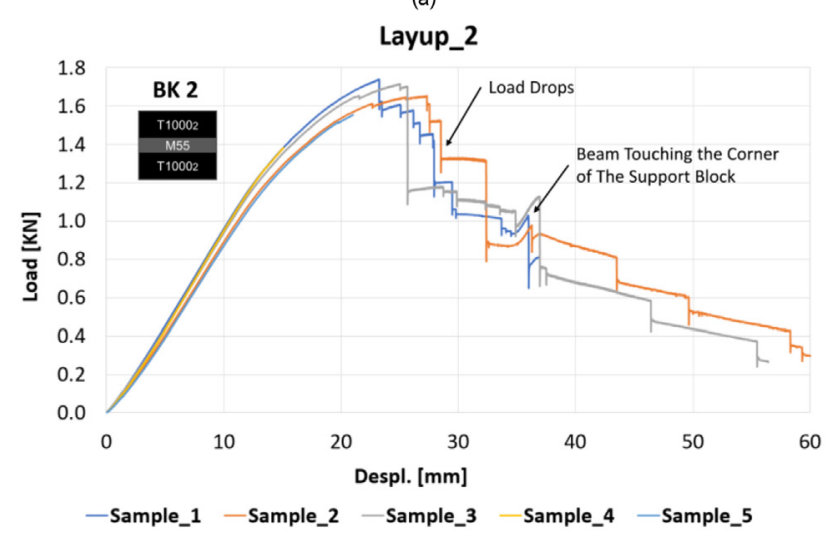

(b)

Fig. 9. Load-displacement curves obtained directly from the loading machine including interrupted samples for (a) Layup 1 and (b) Layup 2, where BK1 and BK2 refer to building block 1 and building block 2 .

\subsection{Strain gauge results}

To capture local tensile strain at the middle of the span of the beam, strain gauges were located at the bottom carbon ply. The maximum measured strains are associated with the failure of the bottom surface T1000 layers in tension, leading to strain gauges being debonded. The average strain at which the linear elastic behaviour changes is found by fitting two trendlines before and after the nonlinear point for each

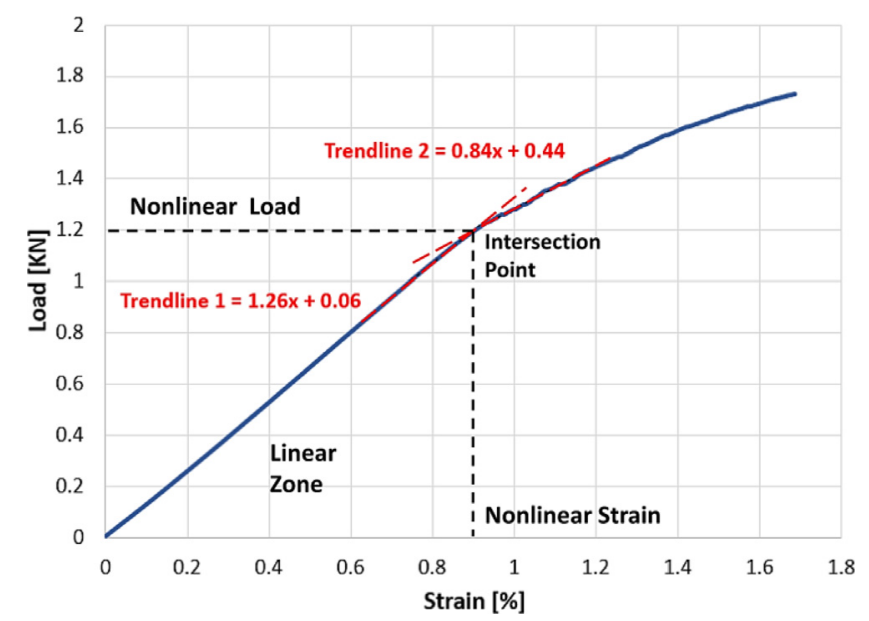

Fig. 10. Definition of the nonlinear point through the intersection of trendlines and calculation of the nonlinear strain and load. specimen and averaging, Fig. 10 shows a schematic description. Fig. 11 shows the load-strain curves where both layups display similar behaviour. At the early stage of loading, the behaviour is linear-elastic and at loads higher than $1.2 \mathrm{kN}$, both layups show a non-linear response. For layup 1 the average strain at the non-linear initiation point corresponds to $0.90 \pm 0.06 \%$ at $1.20 \pm 0.02 \mathrm{kN}$ and for layup 2 , it corresponds to $0.94 \pm 0.01 \%$ at $1.21 \pm 0.02 \mathrm{kN}$. Fig. 11 also shows the prediction of the linear-elastic behaviour of the bottom T1000 ply using beam theory. The strain-force value calculated based on beam theory shows a good agreement with the experimental results measured with strain gauges. Fig. 12 shows the strain distribution for both layups through the thickness using beam theory for an applied force of $1.2 \mathrm{kN}$, which corresponds to the load at the non-linear initiation point.

Fig. 12 shows that the maximum tensile strains at the bottom carbon T1000 ply are $0.91 \%$ and $0.95 \%$ for layup 1 and layup 2 respectively, which are very close to the experimental results using strain gauges $(0.90 \%$ for layup 1 and $0.94 \%$ for layup 2$)$. These strain values are below the tensile failure strain of T1000, 2.2\%. According to Fig. 12 , at $1.2 \mathrm{kN}$ the strain in the bottom M55 layer is equal to $0.85 \%$ and $0.89 \%$ for layup 1 and layup 2 respectively, slightly greater than the quoted tensile failure strain of M55 fibres, $0.8 \%$ (see Table 1). The maximum compressive strain for $\mathrm{T} 1000$ at $1.2 \mathrm{kN}$ corresponds to $0.54 \%$ and $0.58 \%$ for layup 1 and layup 2 respectively. These values are lower than the compressive failure strain of T1000 $(0.95 \%)$. On the other hand, for M55 plies the compressive strain at $1.2 \mathrm{kN}$ for layup 1 is $0.57 \%$ and $0.55 \%$ for layup 2 , which are similar to the compressive failure strain of M55 (0.56\%). This suggests that the nonlinear initia-

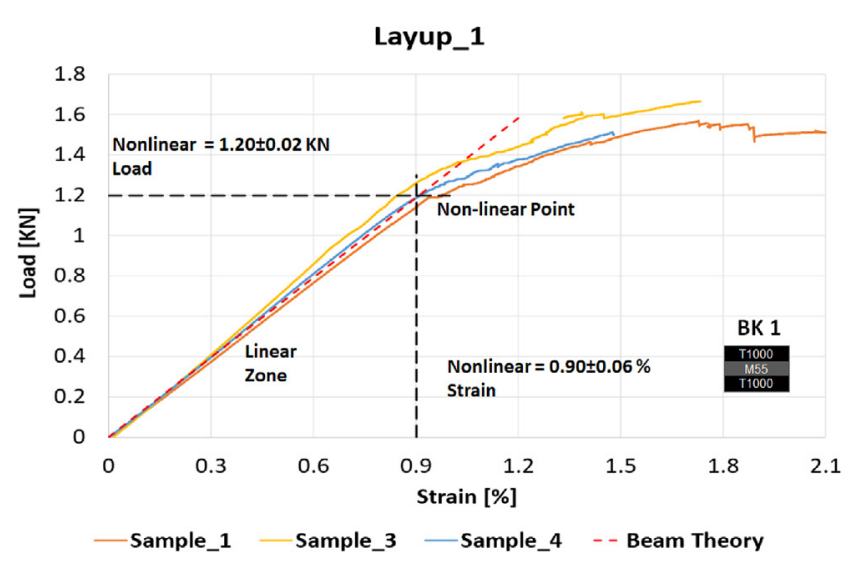

(a)

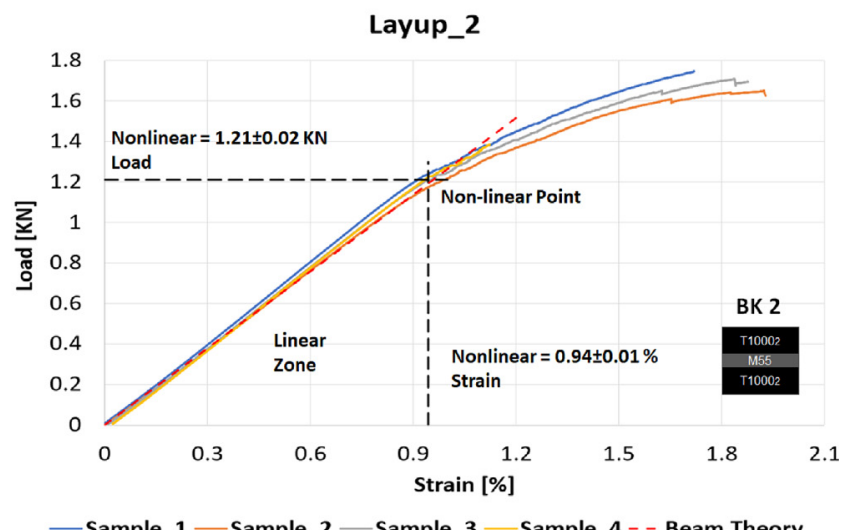

(b)

Fig. 11. Load-strain curves obtained using the strain gauge at the middle of the beam on the bottom T1000 carbon ply for (a) Layup 1 and (b) Layup 2, where BK1 and BK2 refer to building block 1 and building block 2 . 


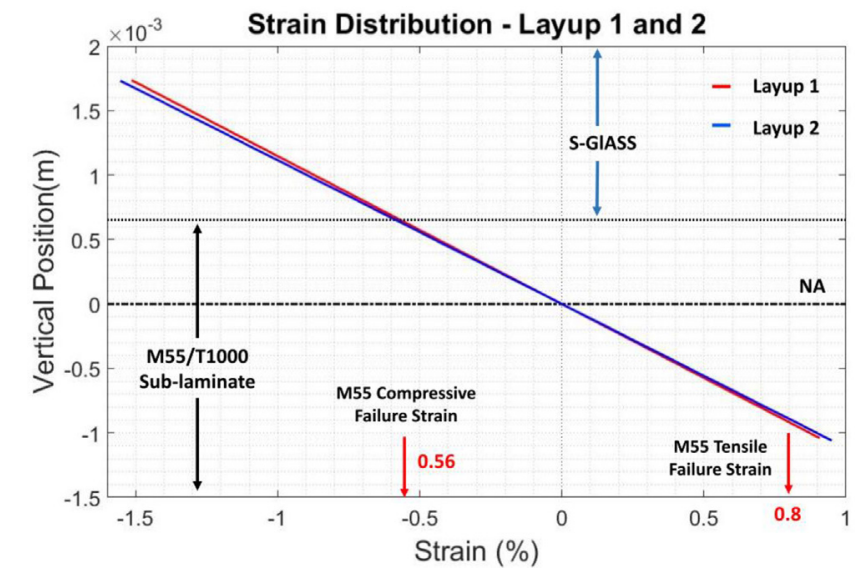

Fig. 12. Strain diagrams of layups 1 and 2 at the non-linear point with a load of $1.2 \mathrm{kN}$.

tion point is related to the starting of M55 fragmentation in both tension and compression at similar loads.

Finally, according to Fig. 12 the maximum strain on the compressive side is $1.51 \%$ and $1.55 \%$ at the surface ply of S-Glass for layup 1 and layup 2 respectively at $1.2 \mathrm{kN}$, which is lower than the compressive failure strain of S-Glass, $2.33 \%$ as reported in Table 1.

\subsection{Microscopy results}

The samples were interrupted before their first load-drop and above $1.2 \mathrm{kN}$ and beyond the first load-drop. Because the findings are similar for both layups, the discussion of this section will be focused only on layup 1 , however, the results are equivalent for layup 2. Fig. 13 shows the load-displacement curves of the samples interrupted for layup 1 , one of the samples was interrupted at $14.9 \mathrm{~mm}$ and the other one after load drop at $27.5 \mathrm{~mm}$ applied displacement.

The sample interrupted before the load drop was analysed using an optical microscope as shown in Fig. 14. Evidence of the M55 plies fragmentation in tension is highlighted with red horizontal arrows whereas T1000 layers are intact showing no damage, see Fig. 14a. These results are in agreement with the failure sequence introduced in section 2.3, see Fig. 5 and Fig. 6, where M55 plies are predicted to fail and fragment, long before T1000 plies in tension. As indicated in Fig. 14c, no evidence of failure in compression was observed for the sample interrupted before the load drop despite the failure order

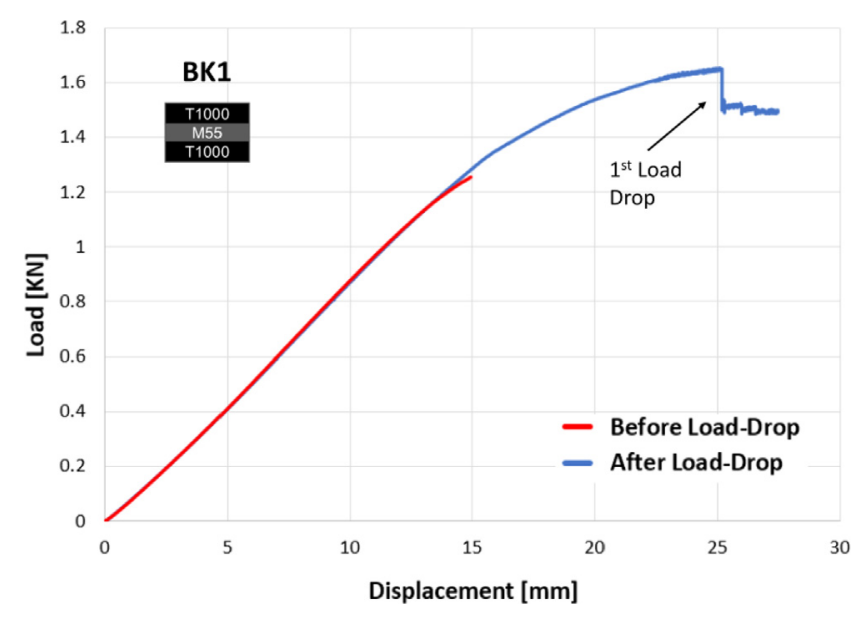

Fig. 13. Load-Displacement curves of samples of layup 1 used in the microscopy analysis, were BK refers to building block 1 .

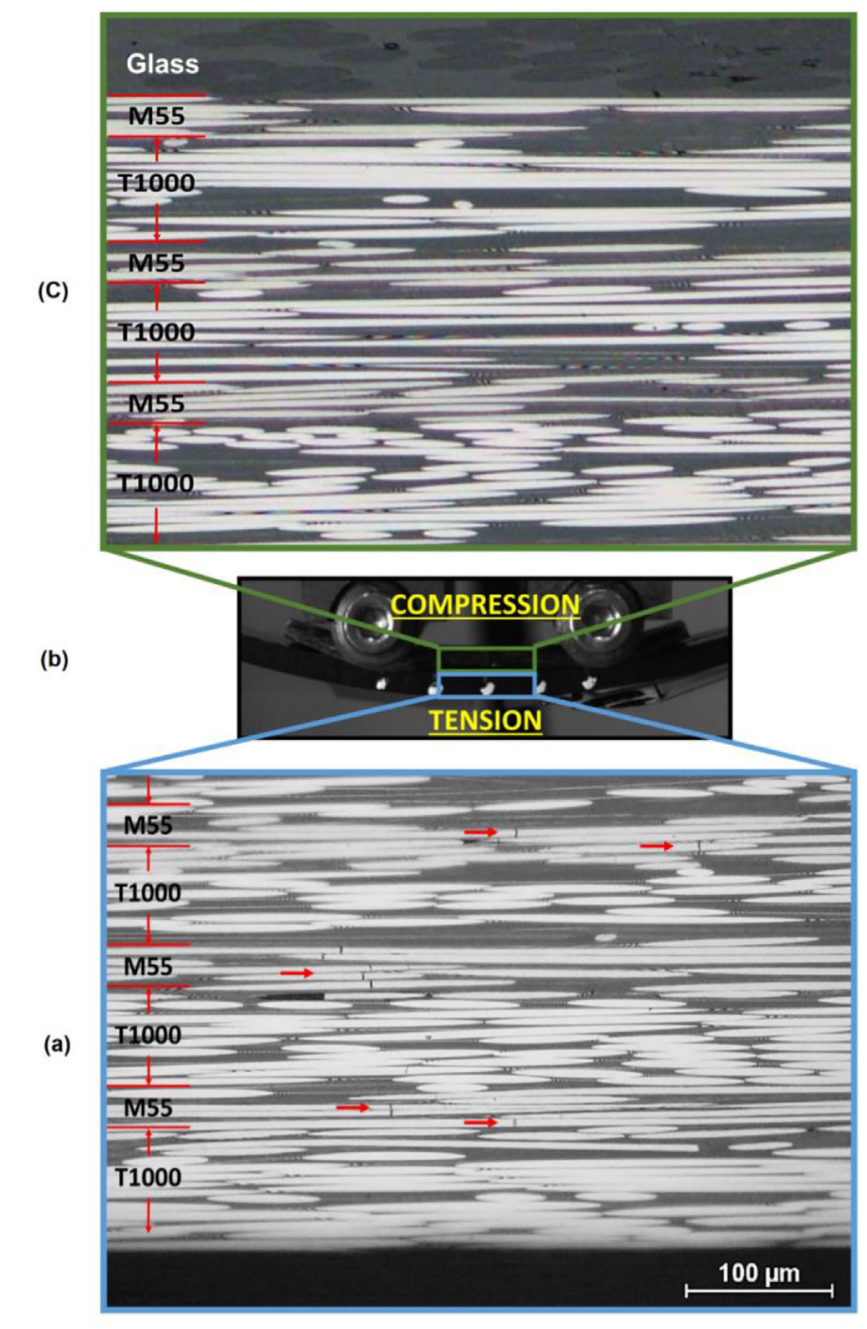

Fig. 14. Microscopy observation using $10 \mathrm{X}$ objective lens. Tensile and compression side of Layup 1 before load drop, interrupted at $14.9 \mathrm{~mm}$ applied displacement, (a) fragmentation of M55 plies in tension, (b) Layup 1 under load and (c) compression side of the sample.

shown in Fig. 5 and Fig. 6 indicating that the top M55 ply would be expected to fail next after the M55 ply in tension. As mentioned before, this result is probably because the earlier failure of M55 plies in tension modifies the position of the neutral axis, delaying the failure of the M55 plies in compression.

The same process was carried out for the sample interrupted after the first load drop. Fragmentation of M55 plies, as well as delamination, was observed in the tensile side of the beam as shown in Fig. 15a. The fragmentations and delaminations are highlighted by small horizontal red arrows in Fig. 15a. No evidence of fragmentation or damage was observed in the T1000 layers that are still attached nearer the middle of the beam. This means that the failed T1000 layers at the load drop, fracture only at one point along the length of the specimen and then delaminate, resulting in the brush-like failure appearance on the tensile side as shown in Fig. 15b.

On the compression side, cracks in the M55 plies were identified for the specimen loaded beyond the first load drop as shown by the red arrows in Fig. 15c. Similar to the results reported in [31,32,33], most of the identified cracks in compression are oriented at an angle between $\pm 45^{\circ}$ to $\pm 60^{\circ}$ relative to the fibre direction, which suggests that the fractures were caused by translaminar shear without kinking. Finally, it is worth to mention that no failure was found in either SGlass or the T1000 plies in compression, which means the proposed 


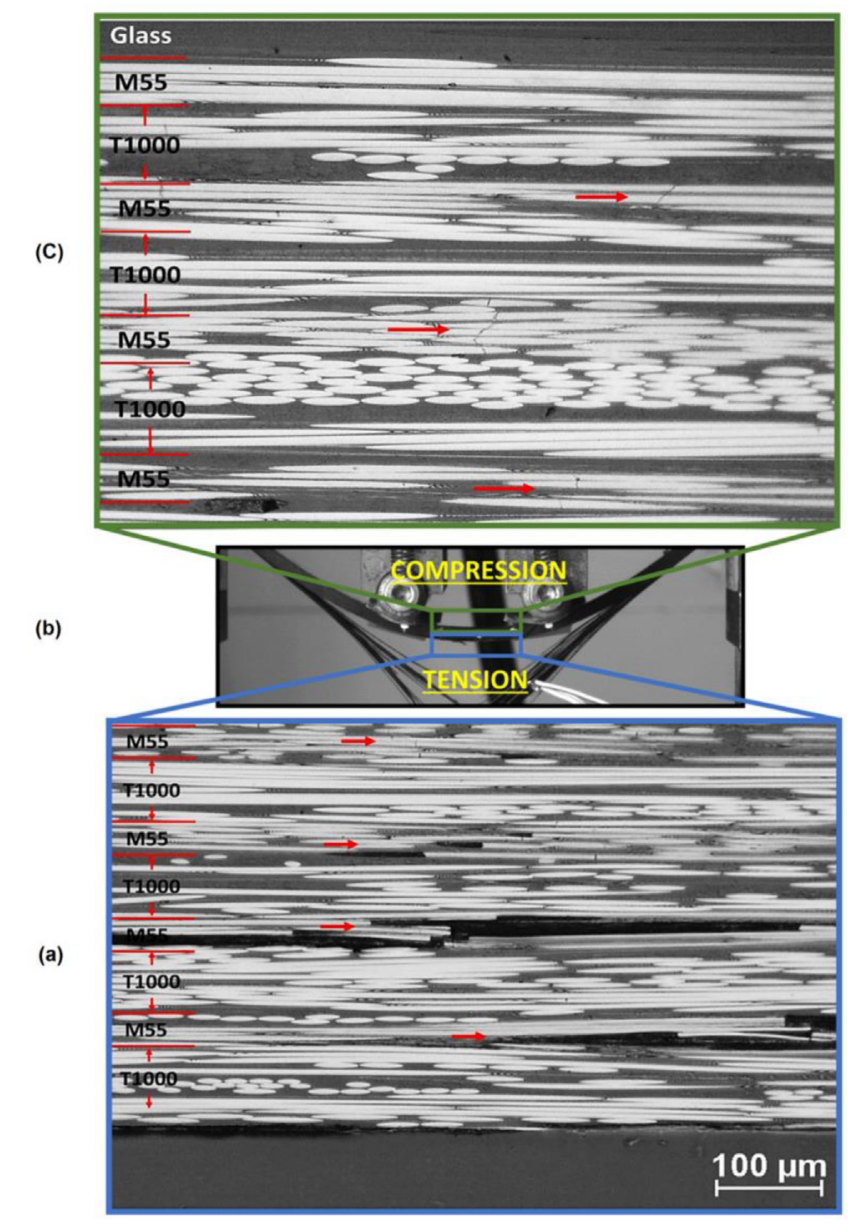

Fig. 15. Microscopy images using $10 \mathrm{X}$ objective lens. Tensile and compression side of Layup_1 interrupted after the first load drop at $27.5 \mathrm{~mm}$ applied displacement, (a) fragmentation and delamination of M55 plies in tension, (b) Layup 1 under the load showing the brush-like failure and (c) shear cracking of M55 plies in compression.

stacking sequences, and the materials selected for the layups provide a good margin between compressive and tensile failure.

\section{Conclusions}

The methodology proposed in this paper successfully achieved gradual failure of hybrid asymmetric composite laminates under flexural loading, producing highly-nonlinear load-displacement curves and progressive brush-like failure with large deformations. Implementing damage mode maps, it was possible to design a suitable building block for the carbon/carbon sub-laminate promoting a fragmentation damage mode in tension. Knowing the failure sequence of the plies, the optimum architecture of the layups was identified, obtaining a safe margin between compressive and tension failure and avoiding compressive failure initiation. Both proposed layups showed gradual failure behaviour as well as similar results in terms of load-displacement, load-strain curves, failure mechanisms and energy absorption.

The micrographs confirmed the predicted failure mechanisms and helped to understand the details of the failure sequence. It was observed that in the non-linear part of the load-displacement curve and before any load drop, the bottom M55 layers on the tensile side started to fragment. At larger applied displacements after the load drop, not only fragmentation in the M55 plies in tension is observed, but also locally dispersed delamination at the M55/T1000 interface.
At the same applied displacement, fragmentation was observed in the top M55 plies under compression. No damage was observed in the T1000 and S-Glass layers on the compressive side, showing that the suggested layups were successful in suppressing unstable compressive failure mechanisms. Finally, the bottom surface T1000 plies fail in tension, producing a complete delamination of the M55/T1000 building block in the form of a brush-like failure from the intact part of the beam. This creates a rather small load drop in the load-displacement curve and continues as further displacement is applied, leading to the second-bottom building block failing and separating from the beam. The gradual separation of the building blocks on the tensile side results in a gradual neutral axis shift to the top of the beam, further reducing the risk of having a compressive failure.

\section{Declaration of Competing Interest}

The authors declare that they have no known competing financial interests or personal relationships that could have appeared to influence the work reported in this paper.

\section{Acknowledgements}

The authors acknowledge the financial supports provided by the Royal Academy of Engineering and the Newton Fund: IndustryAcademia Partnership Programme, IAPP1/100149 as well as the UK Engineering and Physical Sciences Research Council (EPSRC) Programme Grant EP/I02946X/1 on High-Performance Ductile Composite Technology in collaboration with Imperial College, London. Author G. Idarraga would like to thanks Colciencias of the Colombian government for the Doctoral grant, Colciencias, call 647, Sapiencia of the municipality of Medellín for the funding call Enlaza-Mundos programme 2017 and The National University of Colombia. The authors would like also acknowledge and thank Mr Ellis Hills for initial Matlab code developments, Mrs Fatemeh Jalalvand for editing the photo in Fig. 9 and Dr. Alessia Prato for her support in the manufacture of the layups.

\section{References}

[1] Hayashi T. Development of new material properties by hybrid composition. 1st report, Fukugo Zair. Compos Mater 1972;1:18-20.

[2] Summerscales J, Short D. Carbon fibre and glass fibre hybrid reinforced plastics. Composites 1978;9(3):157-66.

[3] Manders PW, Bader MG. The strength of hybrid glass/carbon fibre composites. J Mater Sci 1981;16(8):2233-45.

[4] Czél G, Wisnom MR. Demonstration of pseudo-ductility in high performance glassepoxy composites by hybridisation with thin-ply carbon prepreg. Compos Part A Appl Sci Manuf 2013;52:23-30.

[5] Swolfs Y, Gorbatikh L, Verpoest I. Fibre hybridisation in polymer composites: A review. Compos A 2014;67:181-200.

[6] Czél G, Jalalvand M, Wisnom MR, Czigány T. Design and characterisation of high performance, pseudo-ductile all-carbon/epoxy unidirectional hybrid composites. Compos Part B Eng 2017;111:348-56.

[7] Swolfs Y, Verpoest I, Gorbatikh L. Recent advances in fibre-hybrid composites: materials selection, opportunities and applications. Int Mater Rev 2019;64 (4):181-215.

[8] Suwarta P, Fotouhi M, Czél G, Longana M, Wisnom MR. Fatigue behaviour of pseudo-ductile unidirectional thin-ply carbon/epoxyglass/epoxy hybrid composites. Compos Struct 2019;224:110996.

[9] Jalalvand M, Czél G, Wisnom MR. Numerical modelling of the damage modes in UD thin carbon/glass hybrid laminates. Compos Sci Technol 2014;94:39-47.

[10] Swolfs Y, Verpoest I, Gorbatikh L. A review of input data and modelling assumptions in longitudinal strength models for unidirectional fibre-reinforced composites. Compos Struct 2016;150:153-72.

[11] Czél G, Jalalvand M, Wisnom MR. Design and characterisation of advanced pseudo-ductile unidirectional thin-ply carbon/epoxy-glass/epoxy hybrid composites. Compos Struct 2016;143:362-70.

[12] Wisnom MR, Czel G, Swolfs Y, Jalalvand M, Gorbatikh L, Verpoest I. Hybrid effects in thin ply carbon/glass unidirectional laminates: Accurate experimental determination and prediction. Compos A 2016;88:131-9.

[13] Guerrero JM, Mayugo JA, Costa J, Turon A. A 3D Progressive Failure Model for predicting pseudo-ductility in hybrid unidirectional composite materials under fibre tensile loading. Compos Part A Appl Sci Manuf 2018;107:579-91. 
[14] Sihn S, Kim RY, Kawabe K, Tsai SW. Experimental studies of thin-ply laminated composites. Compos Sci Technol 2007;67:996-1008.

[15] Yokozeki T, Kuroda A, Yoshimura A, Ogasawara T, Aoki T. Damage characterization in thin-ply composite laminates under out-of-plane transverse loadings. Compos Struct 2010;93(1):49-57.

[16] Saito H, Morita M, Kawabe K, Kanesaki M, Takeuchi H, Tanaka M, et al. Effect of ply-thickness on impact damage morphology in CFRP laminates. J Reinf Plast Compos 2011;30(13):1097-106.

[17] Amacher R, Cugnoni J, Botsis J, Sorensen L, Smith W, Dransfeld C. Thin ply composites: Experimental characterization and modeling of size-effects. Compos Sci Technol 2014;101:121-32.

[18] Galos J. Thin-ply composite laminates: a review. Compos Struct 2020;236:111920. https://doi.org/10.1016/j.compstruct.2020.111920.

[19] Jalalvand M, Czél G, Wisnom MR. Damage analysis of pseudo-ductile thin-ply UD hybrid composites - a new analytical method. Compos A 2015;69:83-93.

[20] Jalalvand M, Czél G, Wisnom MR. Parametric study of failure mechanisms and optimal configurations of pseudo-ductile thin-ply UD hybrid composites. Compos Part A Appl Sci Manuf 2015;74:123-31.

[21] Giancaspro JW, Papakonstantinou CG, Balaguru PN. Flexural response of inorganic hybrid composites with E-Glass and Carbon fibers. J Eng Mater Technol 2010;132:021005e1-8.

[22] Ary Subagia IDG, Kim Y, Tijing LD, Kim CS, Shon HK. Effect of stacking sequence on the flexural properties of hybrid composites reinforced with carbon and basalt fibers. Compos B Eng 2014;58:251-8.

[23] Kalantari M, Dong C, Davies IJ. Multi-objective analysis for optimal and robust design of unidirectional glass/carbon fibre reinforced hybrid epoxy composites under flexural loading. Compos Part B Eng 2016;84:130-9.

[24] Kalantari M, Dong C, Davies IJ. Effect of matrix voids, fibre misalignment and thickness variation on multi-objective robust optimization of carbon/glass fibrereinforced hybrid composites under flexural loading. Compos B 2017;123:136-47.
[25] Sudarisman, Davies IJ. Flexural failure of unidirectional hybrid fibre-reinforced polymer (FRP) composites containing different grades of glass fibre. Adv Mater Res 2008;41-42:357-62.

[26] Sudarisman, de San Miguel B, Davies IJ. The effect of partial substitution of E-glass fibre for carbon fibre on the mechanical properties of CFRP composites. Proc Int Conf Mater Metall Technol (ICOMMET 2009) 2009:125-8.

[27] Dong Chensong, Davies Ian J. Optimal design for the flexural behaviour of glass and carbon fibre reinforced polymer hybrid composites. Mater Des 2012;37:450-7.

[28] Dong C, Davies IJ. Effect of stacking sequence on the flexural properties of carbon and glass fibre-reinforced hybrid composites. Adv Compos Hybrid Mater 2018;1:530-40.

[29] Wisnom MR. The effect of specimen size on the bending strength of unidirectional carbon fibre-epoxy. Compos Struct 1991;18(1):47-63.

[30] Wisnom MR. On the high compressive strains achieved in bending tests on unidirectional carbon-fibre/epoxy. Compos Sci Technol 1992;43(3):229-35.

[31] Czél Gergely, Jalalvand Meisam, Wisnom Michael R. Hybrid specimens eliminating stress concentrations in tensile and compressive testing of unidirectional composites. Compos A 2016;91:436-47.

[32] Czél G, Suwarta P, Jalalvand M, Wisnom MR. Investigation of the compression performance and failure mechanism of pseudo-ductile thin-ply hybrid composites. 21st International Conference on Composite Materials Xi'an, 20-25th August 2017, 2017.

[33] Wu XJD, Fuller MR. Wisnom Combining the non-linearity of angle-plies and fibre fragmentation in carbon fibre laminates under compressive loading. 21st International Conference on Composite Materials Xi'an, 20-25th August 2017, 2017.

[34] Ueda Masahito, Saito Wataru, Imahori Ryuma, Kanazawa Daichi, Jeong Tae-Kun. Longitudinal direct compression test of a single carbon fiber in a scanning electron microscope. Compos Part A Appl Sci Manuf 2014;67:96-101. 